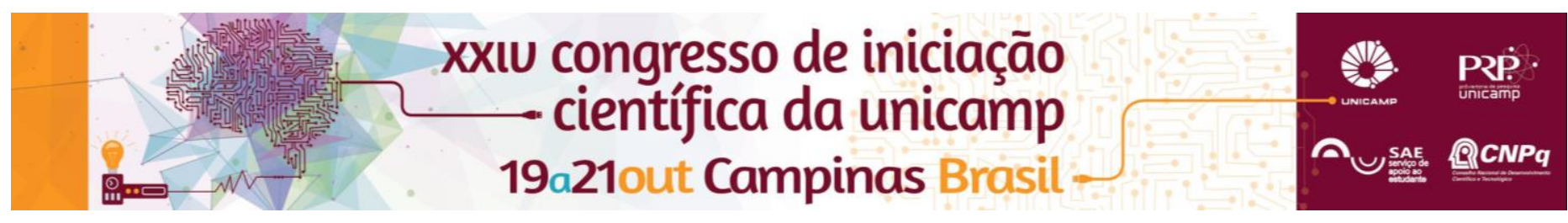

\title{
Prospecting and proposing interactive activities for learning the concepts of Computer Organization and Architecture undergraduate class.
}

\author{
Fernanda M. Gravena*, André Leon S. Gradvohl.
}

\begin{abstract}
The Computer Organization and Architecture classes are offered in the first year of undergraduate courses related to Computer Technology. Many students present difficulties to understand the concepts of the discipline. The result of this project is a survey of selected software tools according to specific criteria and the development of a website containing activities with resolutions of exercises using these tools. The goal is to help the students improve their performance in the discipline.
\end{abstract}

\section{Key words:}

Organization and Architecture, Learning support, Education.

\section{Introduction}

According to the Brazilian Ministry of Education (2012), the Computer Organization and Architecture (COA) course is a mandatory class for bachelors and education degree in computer courses.

New students in the computer science field often have several difficulties to comprehend the concepts presented in COA classes. According to Herman, G. L et al. (2012), students who have this difficulty are those who have a poor knowledge in general logic. Another research conducted by Mirmotahari, Holmboe, and Kaasboll (2003) at the University of Oslo found that the biggest difficulty for students is related to Boolean algebra and Assembler programming.

As a way to improve the learning process, some professors decide to use tools during the course. The purpose of using these simulators is to improve students' understanding of the concepts addressed by the professor.

Therefore, this project presents some tools that could be used in classes as a teaching complement of the COA course. The goal of this project is to make a literature review of the software tools, and suggest a set of practical activities that will be resolved in the pointed tools and thus minimize the doubts that arise during the semester.

\section{Results and Discussion}

For the preparation of this study, we did a literature review in the literature bases IEEE Xplore Digital Library and ACM Digital Library was done. To filter the results and find specific texts to the subject of the discipline we used the following keywords: Simulators, Computer Architecture, Computer Organization, Education, Logic Simulator, Boolean Algebra, Assembler, Logic Circuits.

We installed this software on computers and then we evaluated them. To evaluate this software, we defined seven criteria: language, intuitive, have tutorials, download, and installation, operating systems, and dependence on other software, free or paid.
Cedar Logic Simulator, CPU-8E, K-map, Logic Friday, Logic.ly, Logic Works, LogiSIM, LogiSIM Computer Assembler, Multimedia Logic, and SPIM. Eight of the eleven simulators found approaches logical functions and combinational circuits.

After selecting the tools, we tested all of them on Windows and Linux operating systems.

We also developed a set of practical activities with resolutions on selected simulators. All activities are on a website, which is available to everyone.

\section{Conclusions}

From the analysis, we concluded that not all software found in scientific papers or through web search covers all the concepts of the COA course. The reason for this is that the goals of each software usually focus on a specific concept or closely related concepts.

Thus, we believe it is necessary to use not one but a set of simulators, as well as activities that go beyond the use of software tools, to cover all concepts of the Computer Organization and Architecture undergraduate course.

\section{Acknowledgement}

The authors would like to thank the School of Technology, University of Campinas (Unicamp) for the support through the development of this study.

\footnotetext{
HERMAN, G. L.; LOUI, M. C.; KACZMARCZYK, L.; ZILLES, C. "Describing the What and Why of Students' Difficulties in Boolean Logic" ACM Trans. Comput. Educ., vol. 12, no. 1, pp. 1-28, Mar. 2012.

2 MIRMOTAHARI, O.; HOLMBOE, C.; KAASBØLL, J. "Difficulties learning computer architecture” ACM SIGCSE Bull., vol. 35, no. 3, p. 247, Set. 2003
} 